\title{
Percutaneous vertebroplasty in the management of vertebral lesions
}

\author{
S. Purkayastha, A. K. Gupta, T. R. Kapilamoorthy, C. Kesavadas, B. Thomas, T. Krishnamoorthy, N. \\ K. Bodhey \\ Department of Radiology, Sree Chitra Tirunal Institute of Medical Sciences and Technology, Trivandrum, Kerala, India
}

\begin{abstract}
Background: Debilitating backache due to different types of vertebral lesions is a common cause of morbidity in all age groups. Percutaneous vertebroplasty (PV) gives substantial pain relief and stabilizes the weak vertebrae. Most of the information regarding PV comes from the Western literature. The effect of PV in our population should be studied. Aims: The primary objective is to assess the therapeutic benefit of PV in alleviating back pain and improving the functional status in patients with painful pathologic vertebrae. The secondary objectives are to study the technical aspects of the procedure and their relation to outcome and complications. Settings and Design: This is a retrospective hospital-based (tertiary teaching hospital) study. Materials and Methods: From January 2001 to December 2004, 46 patients underwent PV procedures. Sixty-five vertebroplasties were done in 13 males and 33 female patients. Twenty-four (36.92\%) procedures were done for osteoporotic compression collapse, $26(40.0 \%)$ for hemangioma, and $15(23.07 \%)$ for different vertebral body tumors and metastasis. The Wilcoxon signed rank test was used to evaluate the statistical significance of differences between the preoperative and postoperative levels of pain, mobility and analgesic usage. Results: Most of the patients had pain relief within $48 \mathrm{~h}$. Only minor side effects were encountered. No patient had any deficit related to the procedure. On follow up of 3-48 months, all patients had statistically significant improvement in clinical condition $(P<0.001)$. Conclusion: Percutaneous vertebroplasty is a safe and effective procedure in relieving debilitating backache and can be used to treat vertebral lesions in selected cases.
\end{abstract}

Key Words: Backache, bone cement, percutaneous vertebroplasty

Percutaneous vertebroplasty (PV) was described in 1987 for the treatment of aggressive vertebral hemangioma. ${ }^{[1]}$ It was later applied to osteolytic metastasis and osteoporotic compression fractures. ${ }^{[2]-[10]}$ The goal of PV is to alleviate spinal pain and strengthen the vertebrae through percutaneous injection of cement in to the vertebral body.

In $80-90 \%$ of cases, PV leads to a durable partial or complete pain reduction. Destruction of the posterior vertebral wall, with or without compression of the spinal canal, complete loss of vertebral body height, and presence of osteoblastic metastatic lesion was considered as relative contraindications. ${ }^{[5],[10]}$ Procedural complications such as extravasation of cement into the spinal canal, neural foramen, paraspinal veins, or disc space have been reported in 11-73\% of the procedures. ${ }^{[2],[3],[5],[9]-[11]}$

This study was done to assess the therapeutic benefit of PV in alleviating back pain and improving the functional status in patients with painful pathologic vertebrae.

\section{Materials and methods}

This retrospective study was conducted at our institution between January 2001 and December 2004. Sixty-five consecutive PV procedures were performed in 46 patients. Thirty-three patients $(71.73 \%)$ were women and $13(28.26 \%)$ were men, with age range of $13-77$ years (mean, 57 years). Our institutional review board approved PV. All patients presented with moderate to severe backache. In 15 $(62.5 \%)$ of 24 osteoporotic fractures, $66.66 \%$ (10 of 15 ) of hemangiomas, and $79.92 \%$ of tumors, back pain was of less than 6 months duration. In $36.8 \%$ of lesions (only patients with hemangioma and osteoporotic fracture), backache was of more than 1 year duration. Thirty-three patients had local tenderness. Twenty-five patients had lower limb weakness and out of them 20 patients had Grade 4/5 power with no imaging evidence of cord pathology. The other five patients $(10.86 \%)$ had Grade $2-3 / 5$ power, urinary retention, and they were wheel-chair bound. Their imaging showed moderate cord compression. Seven patients $(15.21 \%)$ had mild sensory deficits. Fifteen patients $(32.6 \%)$ required minimal occasional assistance in their day-to-day work because of pain. Thirty-one patients used oral analgesics based on their needs, 13 patients used on 4-6-hour schedule and two patients required parenteral non-narcotic opoids.

Indications for PV were benign compression fractures, 
hemangioma, and painful neoplastic conditions. All patients were referred for pain resistant to conventional medical management, including bed rest, opioid analgesies, and/or braces. Patient selection was limited to persons with focal, intense deep pain associated with imaging evidence of vertebral lesions. Patients having imaging evidence of other causes of pain such as herniated disc, infections, etc., did not undergo PV. Severe cardiopulmonary disease, coagulopathy and local infection were contraindications for treatment. Most patients on referral had MR imaging or, less often, a combination of conventional radiography, computerized tomography (CT) imaging. Magnetic resonance imaging (MRI), and CT were performed in patients, consulting with conventional radiographs only. Compression fractures with severe loss of vertebral body height and/or mild posterior wall retropulsion were not considered contraindications in our series. Proper systemic and neurological examinations were performed in all patients. Routine laboratory investigations and cardiological work-up were done in all. Informed consent was obtained from all patients after a detailed review of the potential risks and benefits of the procedure. The potential complications specified were bleeding at the puncture site, bone infection or fracture, damage to nerve, or cord, extravasation of cement into surrounding tissue, and pulmonary embolism.

\section{Percutaneous vertebroplasty technique}

Procedures were performed under local anesthesia or conscious sedation monitored by anesthetists. Sedation was obtained by intravenous administration of fentanyl $(25-100 \mathrm{mg})$ and midazolam $(0.25-$ $2.00 \mathrm{mg}$ ). No prophylactic antibiotic therapy was given. All thoracic and lumbar PV procedures performed with the patient prone on the angiography table. The fluoroscopy tube was angled to project pedicle end-on over the targeted vertebral body. Local anesthesia of skin surface and pedicle periostium was obtained with $4 \%$ lidocaine. An 11-gauge or 13-gauge needle (M1/M2, Cook, Bloomington, IN, USA) was advanced into the vertebral body under fluoroscopic control and was placed in the lower anterior half of the vertebral body. Slightly posterior needle positions were acceptable in compressed vertebrae with a steep pedicle angulation. A lateral-to-medial angulation bringing the tip of the trocar close to the midline of the vertebral body (single-pedicle technique) was used in most cases. Surgical hammer was used to penetrate denser bone. Cervical vertebrae PV were done with patient in supine position through an anterolateral approach. After lateral retraction of neck vessels, the needle was advanced posteromedially under fluoroscopic control to enter the respective vertebral bodies. The tip of the needle was kept in the mid-body level.

The needle stylet was removed from the trocar, and the needle hub was inspected for blood reflux. In cases of substantial reflux, the needle was advanced slightly further. Vertebral phlebography was performed with $2-5 \mathrm{ml}$ of diluted contrast medium (Omnipaque 300; Nycomed, Princeton, NJ, USA) mixed with saline in a 50: 50 ratio. Lateral digital subtraction angiography was performed at the rate of two frames per second during the injection of contrast medium.

Bone cement was prepared by mixing $3-4 \mathrm{mg}$ of sterile barium powder (hospital pharmacy preparation) with $10 \mathrm{mg}$ of powder copolymer (DePuy CMW, Johnson \& Johnson, Blackpool, UK). Then liquid polymerizing agent was mixed till a mixture of toothpaste consistency was achieved.

The paste was taken into a $10-\mathrm{ml}$ syringe, used in turn to fill $1-\mathrm{ml}$ Luer-lok syringes. Owing to high viscosity of the cement, best injection results are possible by using 1-ml syringes. The cement was injected into the vertebral body under continuous fluoroscopic moni- toring in anteroposterior and lateral planes. The injection was discontinued when the degree of vertebral body filling was adequate or unwanted leakage was observed. In cases of early venous filling, the injection of cement was usually resumed after a 20-30-second delay, allowing for completion of vertebral body filling without increasing the venous leak. When the degree of cross filling from the initial injection was insufficient, a contralateral transpedicular approach was performed. The decision to address several levels during the same procedure was based on the degree of patient comfort. For bilateral injection the amount of barium used in the cement paste for second injection was doubled for better cement visualization during injection.

A biopsy was performed coaxially through VP needle in patients with neoplastic lesions and in male patients with primary osteoporosis without an identifiable cause. Patients were observed for 24-72 hour before discharge except for inpatients who underwent laminectomy after PV.

Two experienced radiologists were involved in the procedures, retrieval of data and image analysis. All the clinical data were stored in individual case files in the medical record department and the images were stored in hard copies and optical dises.

Preoperative assessment was conducted on the day of the procedure. Postprocedural assessment is done at 24 hours, 1 week, 1 month, 3 months, and then every 6 months intervals. The same assessor, who conducted the preoperative assessment, performed the follow up. Assessments were conducted for the following clinical parameters:

Pain severity: Using an 11-point ordinal scale $(0=$ no pain; $10=$ most severe pain).

Analgesic requirement: Using a 5-point scale $(0=$ no analgesic use; $4=$ parenteral narcotics administration).

Activity: Using a 5-point scale $(0=$ full activity; $4=$ bedridden $)$. These scales were arbitrary and they have not been formally validated.

\section{Other morphological assessments:}

Percentage of volume of cement filling of vertebrae: This was assessed visually and also correlated with postprocedure imaging. Each vertebral body was divided into equal four sagittal and two axial quadrants and each quadrant is assigned a value of $12.5 \%$ and the filling in each quadrant assessed.

Cement extravasation: Anteroposterior and lateral plain X-rays of spine and postprocedure CT scan were done to assess cement extravasation in different areas.

Measurement of vertebral body height: The vertical height of the vertebral body was measured on the preoperative MR images and on the postoperative CT scans. Measurements were performed of the anterior, central, and posterior vertebral height in the mid-sagittal plane. One untreated vertebral body adjacent to the treated one was measured as a control.

Postprocedure evaluation of complications: It was evaluated in postprocedure imaging and clinical examinations were performed to assess any clinical deficit.

Statistical analysis: The Wilcoxon signed rank test was used to evaluate the statistical significance of differences between the preoperative and postoperative levels of pain, mobility, and analgesic usage.

Other nonparametric test used to assess different scores was Mann-Whitney test. For comparison of proportions and means 
chi-square test and Student's $t$-tests were performed in relevant areas and $P$-value was calculated for evaluation of statistical significance and the statistical analysis was carried out.

\section{Results}

Twenty-four procedures (36.92\%) were done for osteoporotic compression fracture, $26(40.0 \%)$ for hemangioma, and 15 $(23.07 \%)$ procedures for various neoplastic conditions. Of 15 neoplastic vertebrae, 7 were osteoclastoma, 4 were multiple myeloma, 2 were aneurysmal bone cyst, and 2 were vertebral metastasis. All compression fracture patients, $58.8 \%$ hemangiomas were females and males constituted $83.3 \%$ in tumor patients. Statistically significant correlation was seen in sex incidence of different pathologies $(P=0.001$, d.f. 2$)$. One-, two-, three-, and four-level treatments were performed in $33,8,4$, and 1 instances, respectively, for a total of $50 \mathrm{PV}$ sessions. The distribution of vertebral levels $(n=65)$ was as follows: C1-C6, 2; T1-T6, 7; T7-T12, 35; L1-L5, 21. A left transpedicular route was taken in 40 procedures $(61.53 \%)$, right in seven procedures $(10.76 \%)$, and both in 15 procedures $(23.07 \%)$. Three procedures $(4.61 \%)$ were done via a left paravertebral route because of total pedicular destruction by the malignant process. Sixty-one procedures were performed under local anesthesia and four under conscious sedation. Mean duration of procedure was $50.13 \mathrm{~min}$ (SD 8.095). Amount of cement injected (mean) varied amongst different groups. It was $5.6 \mathrm{ml}$ in osteoporotic vertebrae, $5.35 \mathrm{ml}$ in hemangiomas [Figure 1] and $8 \mathrm{ml}$ in vertebrae affected by different tumors. The amount of vertebral filling (mean) was 85.33, 84.82, and $88.67 \%$, respectively, in three groups. No statistically significant correlation was noted between the lesion types and the volume of cement injected $(P=0.048$; d.f. $=2.35)$ and amount

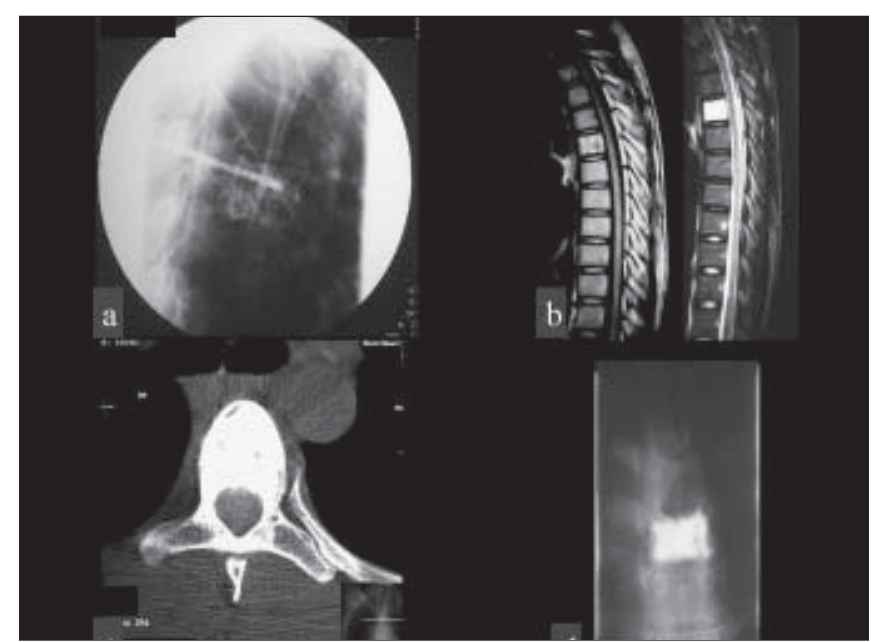

Figure 1: Case 3. (A) D6 hemangioma with vertebroplasty needle in situ. (B) T1 and T2 weighted sagittal magnetic resonance imaging (MRI) scan shows hemangioma of D6 vertebra. (C) Postvertebroplasty computerized tomography (CT) scan shows complete filling of vertebra. (D) X-ray at 6 months shows good result of filling ( $P=0.730$; d.f. 2.35$)$. Thirteen-gauge needle was used in 10 procedures and 11-gauge needle in 28 procedures. Thirteen-gauge needle was mostly used in thoracic level and in two lumbar levels, where there was severe compression of vertebral bodies. The mean amount of cement injected and the percentage of filling by different needle sizes were $6.07 \mathrm{ml}$ and $86.57 \%$ by 11-gauge needles, where as it was $5.30 \mathrm{ml}$ and $83.00 \%$ by 13 -gauge needles. No statistically significant correlation was seen between these groups $(P=0.383,95 \%$ confidence intervals $-0.998,2.541)$. The mean amount of cement injected and mean percentage of filling of vertebrae were $4.3 \mathrm{ml}$ and $76.1 \%$ in cervical levels; $4.4 \mathrm{ml}$ and $77.6 \%$ in D1D6 levels; $5.1 \mathrm{ml}$ and $92.2 \%$ in D7-D12 levels; $7.62 \mathrm{ml}$ and $87.64 \%$ in lumbar levels. Overall correlation between volume of cement injected and \% of filling irrespective of levels was significant $(P £ 0.001$ ). The total number of procedures done in compressed vertebra is $24(33.84 \%)$. Increase in height observed in vertebra $54.16 \%$ of cases (13 of 24 ) and mean amount of cement injected in this group was $5.69 \mathrm{ml}$ [Figure 2]. Postprocedure CT scan at $24 \mathrm{~h}$ was used to determine the initial increase in height of the vertebral body. The scan was repeated at 3 and 6 months specifically in the group to see the status of the increased vertebral bodies. We have not encountered any change in 6 months period. After that we did not repeat CT scans in these patients, as the patients did not complain of any deterioration in their clinical symptoms. Venography was done in $43(66.15 \%)$ procedures. No statistically significant correlation was noted between venography and the amount of cement injected $(P=0.514,95 \%$ confidence intervals $-1.961,3.846)$, the percentage of filling of the vertebra $(P=0.323,95 \%$ confidence intervals $-0.626,18.489)$, and the complications $(0.653$, d.f. $=1)$. Preprocedure hemangioma embolization was done in seven cases. Posterior element alcohol injection was done after five procedures, where

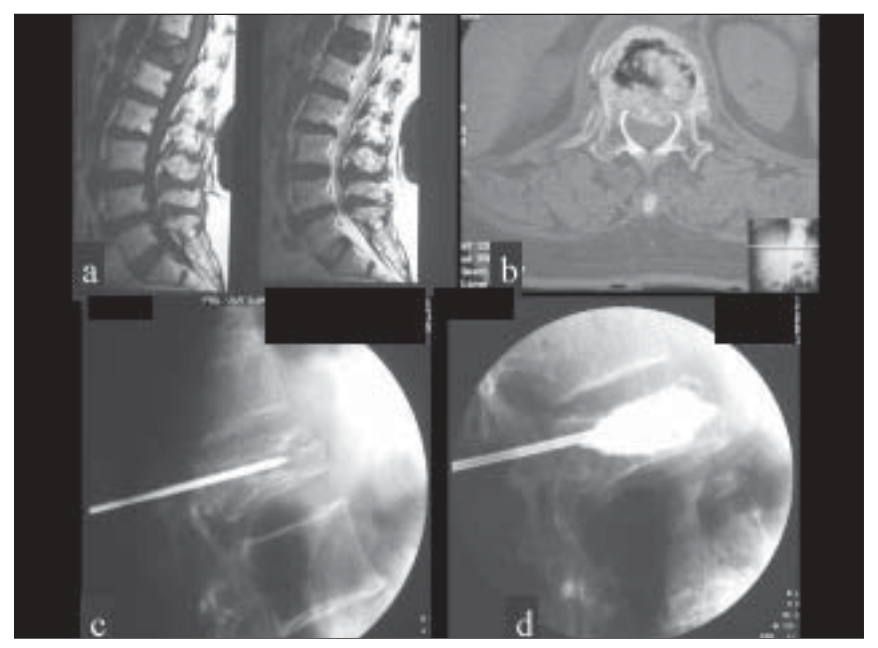

Figure 2: Case 25. (A) T1 and T2 weighted sagittal magnetic resonance imaging (MRI) scan shows D12 osteoporotic collapse. (B) Axial computerized tomography (CT) scan shows vacuum phenomenon. (C) Fluoroscopic image shows needle in vertebra. (D) Postvertebroplasty image shows good filling and increase in body height 
hemangioma involved posterior elements. We combined laminectomy with PV for patients having cord compression [Figure 3]. Laminectomy was done in four of five wheel-chairbound patients. Of them three had osteoclastoma, one had aggressive hemangioma involving vertebral bodies with cord compression. The other wheel-chair-bound patients had aggressive hemangioma, where preprocedure embolization was done. This patient refused surgery. After 3 months, the patient regained power of Grade 4/5 and imaging showed regression of epidural components and then vertebroplasty was performed. In all the above five patients, urinary symptoms disappeared and power came to Grade 4/5 at 1 month of follow up after VP. The patients with tumors received additional radiotherapy and chemotherapy. One patient, who had osteoporotic compression fracture, was taken for second sitting of vertebroplasty because of inadequate filling in the first sitting and persistent pain. The patient became asymptomatic after second sitting of treatment.

No major change in vitals was seen during the procedures. One patient had intraprocedure tachycardia and another patient had postprocedure bradycardia, which was managed with atropine. In $15.21 \%$ of patients analgesics were continued for 5-7 days for minimal residual pain. No patient required analgesics after 1 month of follow up. The mean duration of hospital stay was 3.24 days (1-8 days). In 11 (16.92\%) of procedures minor complications were seen which were clinically insignificant. Prevertebral, paravertebral venous filling and disc space filling were seen in three procedures $(4.61 \%)$, respectively. Mild epidural leak was seen in two procedures (3.07\%). Paravertebral soft tissue extravasation was seen in four procedures $(6.15 \%)$. Pulmonary embolism by cement was seen

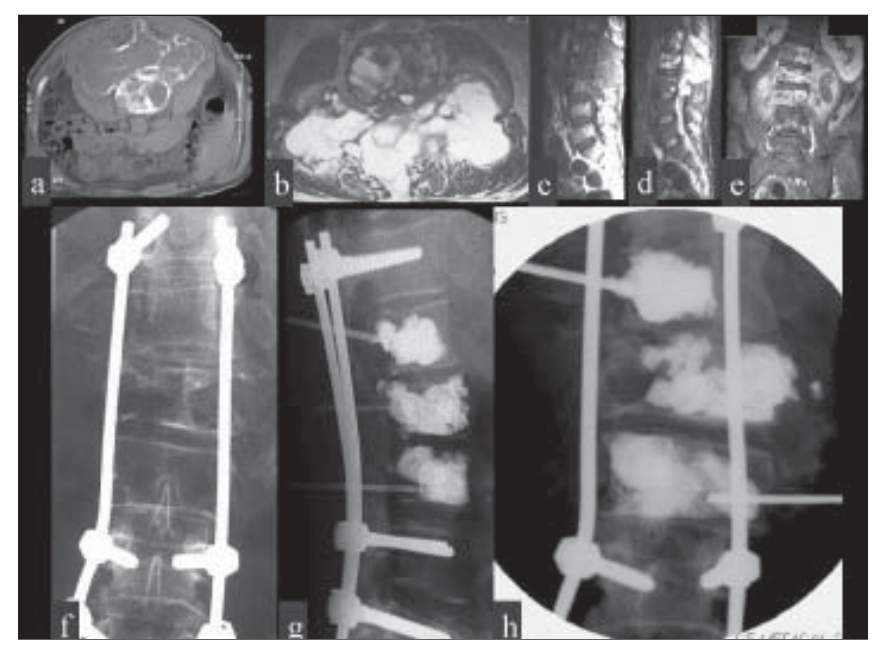

Figure 3: Case 43. (A) Axial computerized tomography (CT) scan; (B) T2 weighted magnetic resonance imaging (MRI) axial image; (C) T1 weighted sagittal MRI; (D) T2 weighted sagittal MRI show the osteoclastoma involving L1-L3 vertebrae; (E) Postcontrast coronal T1 weighted image show the enhancement of osteoclastoma; $(F)$

Prevertebroplasty anteroposterior fluoroscopic image show fixation rod in situ; (G) Postvertebroplasty lateral; (H) Anteroposterior fluoroscopic image show good filling of the vertebrae in one case with out any clinical significance. No statistically significant correlation was noted between the complications and volume of cement injected $(P=0.408,95 \%$ confidence intervals $-1.010,2.481)$ and the percentage of vertebral filling $(P=0.512,95 \%$ confidence intervals $-4.991,9.839)$. Mean pre and postprocedure pain intensity was 6.7 (SD 1.427, median 6.00 and interquartile range 2.00) and 0.05 (SD 0.226 , median 0.00 and interquartile range 0.00$)$, respectively $(P<$ $0.001)$. Mean pre and postprocedure activity scores were 0.84 (SD 1.053, median 1.00 and interquartile range 1.00), and 0.11 (SD 0.388, median 0.00 and interquartile range 0.00 ), respectively, $(P<0.001)$. Mean pre and postprocedure analgesic intake scores were 1.0 (SD 0.465 , median 1.00 and interquartile range 0.00$)$, and 0 , respectively, $(P<0.001)$. The above postprocedure assessments were done after 1 month of follow up. Duration of follow up is 1-48 months. Six months and one year follow up were available for 40 and 29 patients, respectively. All of them were ambulatory and stopped analgesics. Two years and 3 years follow up were available for 20 and 12 patients, respectively. Seven patients with neoplasm were lost to follow up and the rest were asymptomatic. All hemangioma patients were asymptomatic. In nine patients, with osteoporotic collapse, backache was of around 1 year duration. We have not found any difference in outcome in these late treated group as compared to the early ones up to 1 year of follow up. At 2 years, 12 osteoporotic patients (100\%) were asymptomatic. Seven osteoporotic patients have 3 years of follow up. Out of them five patients had recurrence of pain of mild intensity and they occasionally took analgesics for that. No new fractures were seen in these patients and the treated vertebrae were normal imagiologically.

\section{Discussion}

Percutaneous vertebroplasty has been introduced as an effective, minimally invasive procedure for the treatment of painful vertebral lesions and most of the information regarding this procedure comes from the Western experience. ${ }^{[1]-[10]}$ The experience in our population is limited. ${ }^{[12]}$ Percutaneous vertebroplasty was first used for the treatment of aggressive vertebral hemangioma. ${ }^{[1],[13]}$ Deramond et al. treated hemangiomas having epidural component with combinations of PV, alcohol injection and laminectomy and achieved pain reduction in more than $90 \%$ of patients. ${ }^{[14]}$ We treated eight aggressive hemangiomas. Of them, five had mild epidural bulge and three had moderate epidural component and cord compression. Percutaneous vertebroplasty was combined with embolization and/or laminectomy in them. Although surgical decompression was needed for severe cord compression, regression of mild to moderate epidural component was noticed after hemangioma embolization and posterior element alcohol injection. Deramond et al. also noticed regression of aggressive hemangioma after alcohol injection. ${ }^{[14]}$ Immediate pain reduction was achieved in more than $95 \%$ of patients and since 
last 3 years all our hemangioma patients are asymptomatic and independent. Our result validates the findings of previous studies. ${ }^{[1],[9],[10],[14]}$

Destructive vertebral lesion is a common source of morbidity in patients with metastatic disease and multiple myeloma and $30 \%$ of these patients develop symptomatic spinal metastases. Many authors reported post-PV partial or complete pain relief for such lesions in their patients. ${ }^{[3],[15]}$ Pain reduction was achieved in $90 \%$ within $24 \mathrm{~h}$. All patients were pain free and ambulatory up to 1 year of follow up. More than 2 years of follow up are available only for three patients and they are independent. All the patients were sent for adjuvant radiotherapy and/or chemotherapy after vertebroplasty. Our result matches that of previous studies. ${ }^{[3],[14],[15]}$ Although Shimony et al. demonstrated PV to be safe in malignant compression fractures with epidural involvement and we also had good results in our patients when combined with laminectomy and radiotherapy, we still have concerns regarding the use of PV for patients with clinical and radiological signs of spinal cord compression. ${ }^{[16]}$

The Western literature with PV shows 90-100\% pain relief in osteoporotic fractures. ${ }^{[2],[4],[6]}$ Both Cotten et al. and Deramond et al. considered severe vertebral compression a relative contraindication of $\mathrm{PV} \cdot^{[3],[14]}$ But, Peh et al. performed PV for severe osteoporotic collapse (height reduced less than one-third of their originals height) and achieved good result. ${ }^{[17]}$ We performed eight vertebroplasties (33.33\%) for severe collapse. There were no major complications. Our series included 18 vertebrae $(27.69 \%)$, where a breach was noted in the posterior wall with mild epidural bulge. They had no neurological symptoms, so surgical decompression was not considered. The procedure was performed with great care to avoid catastrophic leakage of cement into unwanted areas. However, there were two episodes of disc space filling and paravertebral vein filling which were clinically silent. We recommend slightly higher consistency cement in these cases. At 2 years of follow up, all of them were asymptomatic and independent. However, mild recurrence of pain was seen in five patients after 3 years but radiologically the vertebrae were normal and no new fractures seen. Our result on compression fractures validates the results of previous studies. ${ }^{[2],[4],[6],[7],[9]}$ We achieved statistically significant clinical improvement till the latest follow up in the available patients. Our result are similar to those reported by Kallmes et $a l .{ }^{[18]}$ Different types of cements and opacifiers were used for PV. ${ }^{[14]}$ A $30 \%$ wt./vol mixture produces no practical change in its compressive strength and gives adequate radio-opacity. ${ }^{[19]}$ The cements used in our patients ensured adequate radio-opacity for injection and strength to the vertebrae.

We performed all cases under single plane fluoroscopy but biplane fluoroscopy or combined CT and biplane fluoroscopy is preferred because of simultaneous orthogonal visualization. ${ }^{[9],[20]}$ We do not prefer biopsy in cases of hemangioma as suggested by Deramond et al. ${ }^{[14]}$ We never used any antibiotics but it may be necessary for immunocompromised patients. ${ }^{[6],[20]}$ Some authors have discussed the importance of intraosseous venography, whereas others do not favor its use. $^{[8],[15],[19],[21]-[24]}$ We have not encountered any statistically significant difference in clinical outcome or in complication rate in the procedures done with or without antecedent venography. Our results support the findings of Gaughen et al. ${ }^{[25]}$

Vertebroplasty via bipedicular approach ensures better lesion filling, but we prefer to do unipediculate approach because it is less time consuming and has a lower complication rate. We did not find any statistically significant difference in clinical outcome or cement volume injected in unipediculate versus bipediculate procedures. Our result validates the findings by Kim et al. ${ }^{[26]}$

The principal complication is cement leakage and most of them are clinically silent. ${ }^{[2],[3],[5],[10],[27]}$ Few of them required decompressive surgery. ${ }^{[14],[15]}$ Complication rate is less than $5 \%$ in hemangioma and osteoporotic fractures but slightly more for neoplastic lesions. ${ }^{[1]-[3]}$ In our series, it was less than $5 \%$ in hemangiomas and compression fractures and $9.7 \%$ in neoplastic lesions. One patient had pulmonary embolization and he is asymptomatic up to his latest follow up at 3 years. Vertebral venography can identify potential sites of cement leak. ${ }^{[19]}$ But we did not find any advantage of that in our series. A transient decrease in blood pressure and $\mathrm{HR}$ is generally observed during the injection of cement. ${ }^{[28],[29]}$ Only one patient in our series had intraprocedure tachycardia. The complication rates in our series are no more than previous series.

Although our study represents the effectiveness of $\mathrm{PV}$, it has its limitations. It lacks the prospective randomization of a clinical trial and the limited patient population in each group may lack the power to demonstrate the real effectiveness and complication rate of the procedure in them. In our study experienced operators have performed the procedures. It may be a clinically relevant limitation as in practice; the level of experience varies dramatically. Finally, prospective randomized controlled trials may assist in clarifying the uncertainties that continue to surround the techniques and effectiveness of the procedure in different types of lesion.

\section{Conclusion}

Percutaneous vertebroplasty is safe and effective treatment for painful and destructive vertebral lesions, whether benign or malignant, as well as osteoporotic vertebral fractures in which conservative therapy fails. Vertebroplasty strengthens and stabilizes the diseased vertebral body, gives relief from incapacitating pain and thus enhances the activity level of the patient. A multidisciplinary team should ideally make the decision on treatment because in selected cases of malignant compressive lesions and aggressive hemangioma decompressive surgery or radiotherapy should be combined with 
vertebroplasty for better outcome.

\section{References}

1. Galibert P, Deramond H, Rosat P, Le Gars D. Preliminary note on the treatment of vertebral angioma by percutaneous acrylic vertebroplasty. Neurochirurgie $1987 ; 33: 166-8$.

2. Cortet B, Cotten A, Boutry N, Flipo RM, Duquesnoy B, Chastanet P, et al Percutaneous vertebroplasty in the treatment of osteoporotic vertebral compression fractures: an open prospective study. J Rheumatol. 1999; 26: 2222-8.

3. Cotten A, Dewatre F, Cortet B, Assaker R, Leblond D, Duquesnoy B, et al. Percutaneous vertebroplasty for osteolytic metastases and myeloma: effects of the percentage of lesion filling and the leakage of methyl methacrylate at clinical follow-up. Radiology 1996; 200:525-30

4. Kaemmerlen P, Thiesse P, Bouvard H, Biron P, Mornex F, Jonas P. Percutaneous vertebroplasty in the treatment of metastasis: technique and results. $J$ Radiol 1989; 70:557-62

5. Cotten A, Boutry N, Cortet B, Assaker R, Demondion X, Leblond D, et al Percutaneous vertebroplasty: state of the art. Radiographics 1998; 18: 311 20 .

6. Jensen ME, Evans AJ, Mathis JM, Kallmes DF, Cloft HJ, Dion JE. Percutaneous polymethylmethacrylate vertebroplasty in the treatment of osteoporotic vertebral body compression fractures: technical aspects. AJNR Am J Neuroradiol 1997; 18: 1897 -904

7. Cyteval C, Sarrabere MP, Roux JO, Thomas E, Jorgensen C, Blotman F, et al. Acute osteoporotic vertebral collapse: Open study on percutaneous injection of acrylic surgical cement in 20 patients. A.JR Am .J Roentgenol 1999; 173: 1685 90

8. Barr JD, Barr MS, Lemley T.J, McCann RM. Percutaneous vertebroplasty for pain relief and spinal stabilization. Spine 2000; 25:923-8.

9. Mathis .JM, Barr JD, Belkoff SM, Barr MS, Jensen ME, Deramond H. Percutaneous vertebroplasty: a developing standard of care for vertebral compression fractures. A.JNR Am J Neuroradiol 2001; 22: 373-81.

10. Deramond H, Depriester C, Toussaint P, Galibert P. Percutaneous vertebroplasty. Semin Musculoskelet Radiol 1997; 1: 285-296.

11. Harrington KD. Major neurological complications following PV with PMMA: a case report. J Bone Joint Surg 2001; 83: 1070-3.

12. Nirala AP, Vatsal DK, Husain M, Gupta C, Chawla J, Kumar V, et al. Percutaneous vertebroplasty: An experience of 31 procedures. Neurology India 2003 ; 51: 490-2.

13. Laredo JD, Reizine D, Bard M, Merland JJ. Vertebral hemangiomas: radiologic evaluation. Radiology 1986; 161:183-9.

14. Deramond H, Depriester C, Galibert P, Le Gars D. Percutaneous vertebroplasty with polymethyl meth acryl ate. Technique, indications, and results. Radiol Clin
North Am 1998; 36:533-46.

15. Maynard AS, Jensen ME, Schweickert PA, Marx WF, Short JG, Kallmes DF. Values of bone scan imaging in predicting pain relief from percutaneous vertebroplasty in osteoporotic vertebral fractures. A.JNR Am .J Neuroradiol $2000 ; 21: 1807-12$

16. Shimony JS, Gilula LA, Zeller A.J, Brown DB. Percutaneous vertebroplasty for malignant compression fractures with epidural involvement. Radiology 2004; 232: 846-53.

17. Peh WC, Gilula LA. Additional value of a modified method of intraosseous venography during percutaneous vertebroplasty. A.JR Am J Roentgenol 2003; 180:87-91.

18. Kallmes DF, Schweickert PA, Marx WF, Jensen ME. Vertebroplasty in the mid and upper thoracic spine. A.JNR Am .J Neuroradiol 2002; 23:1117-20.

19. Belkoff SM, Maroney M, Fenton DC, Mathis JM An in vitro biomechanical evaluation of bone cements used in percutaneous vertebroplasty. Bone 1999; $25: 23 \mathrm{~S}-26 \mathrm{~S}$.

20. Gangi A, Kastler BA, Dietemann JL. Percutaneous vertebroplasty guided by a combination of CT and fluoroscopy. A.JNR Am J Neuroradiol 1994; 15:83-6.

21. Hiwatashi A, Moritani T, Numaguchi Y, Westesson PL. Increase in vertebra body height after vertebroplasty. A.JNR Am .J Neuroradiol 2003; 24: 185-9.

22. Jensen ME, Dion JE. Percutaneous vertebroplasty in the treatment of osteoporotic compression fractures. Neuroimaging Clin North Am 2000; 10: 547 68.

23. Cotten A, Boutry N, Cortet B, Assaker R, Demondion X, Leblond D, et al. Percutaneous vertebroplasty: state of the art. Radiographies 1998; 18:311-20.

24. Weill A, Chiras J, Simon JM, Rose M, Sola-Martinez T, Enkaoua E. Spinal metastases: indications for and results of percutaneous injection of acrylic surgical cement. Radiology 1996; 199:241-7.

25. Gaughen JR Jr, Jensen ME, Schweickert PA, Kaufmann T.J, Marx WF, Kallmes DF. Relevance of antecedent venography in percutaneous vertebroplasty for the treatment of osteoporotic compression fractures. A.JNR Am J Neuroradiol 2002; 23: 594-600.

26. Kim AK, Jensen ME, Dion .JE, Schweickert PA, Kaufmann T.J, Kallmes DF. Unilateral transpedicular percutaneous vertebroplasty: initial experience. Radiology 2002; 222: 737-41.

27. Fourney DR, Schomer DF, Nader R, Chlan-Fourney J, Suki D, Ahrar K, et al Percutaneous verteborplasty and kyphoplasty for painful vertebral body fractures in cancer patients. .J Neurosurg Spine 2003; 98:21-30.

28. Phillips H, Cole PV, Lettin AW. Cardiovascular effects of implanted acrylie bone cement. Br Med J 1971; 3:460-1.

29. Duncan JA. Intra-operative collapse or death related to the use of acrylic cement in hip surgery. Anaesthesia 1989; 44:149-53.

\section{Accepted on 15-04-2005}

\section{Invited Comments}

Percutaneous vertebroplasty is a highly effective therapy for selected patients suffering from a variety of painful vertebral lesions. The objective of this procedure is to obtain an analgesic effect by mechanical stabilization in destructive lesions of the spine. The three major indications are aggressive vertebral hemangiomas, severe or refractory pain related to osteoporotic vertebral fractures, and malignant vertebral tumors. Complications are infrequent, but occur essentially in patients with vertebral malignant tumors. This study and many other recently published series ${ }^{[1]}$ have shown similar results: the procedure is technically simple, straightforward, and presents a high-cost effectiveness rate. No sophisticated equipments are needed, patients present a very low-procedural complication rate, and patient's satisfaction is almost guaranteed.

However, as with many other neuroradiological techniques, in order to keep a high-efficacy-to-complication ratio a key issue is adequate patient selection. In order to do so, patients' clinical history and physical examination are of paramount importance. Patients complaining of diffuse, not precise, chronic and irradiated type of pain usually do not benefit from this therapy. Second, a comprehensive evaluation of the very recently obtained neuroradiological examinations is required, anticipating eventual technical problems, limitations, or contraindications. Selection of the vertebral body to be treated is sometimes easy, but multilevel compromise will obscure (and miss) appropriate targeting. In these cases again, physical examination and eventually new neuroradiological studies will be of assistance. Pathological processes affecting vertebral bodies can be very dynamic and neuroradiological studies obtained 1 month ago cannot be realistic today. 
Another point to be reminded is that a significant proportion of patients requiring vertebroplasty are aged and fragile, with long-standing incapacitating diseases. Pre-procedural examinations will be tailored according to every patient's condition, i.e., coagulation studies are part of the routine examinations and sonographic evaluation of lower limbs will be required for immobilized patients.

A last but not least important point is the adequate management of patient expectations regarding pain relief. Vertebroplasty can be spectacular and magical for certain patients and disappointing and ineffective for others. This technique needs always to be part of an integral pain therapy program in a multidisciplinary team approach. Several fac-

\section{Invited Comments}

Severe pain after compression fractures of the spine is a common medical problem. Vertebral compression fractures occur either due to mineral loss of the bone in osteoporosis, or due to vertebral destruction by benign or malignant tumors. Percutaneous vertebroplasty is a procedure used to augment bone and relieve pain through the injection of polymethylmethacrylate (PMMA) into a collapsed vertebral body. In patients with malignancy, the infiltrating tumor destroys the integrity of the vertebrae, causing vertebral collapse with associated severe pain. Regardless of etiology, all patients with vertebral compression fractures suffer disabling and persistent pain for weeks or months.

Surgery is rarely considered for patients with metastatic bone infiltration. Vertebroplasty is useful for the treatment of selected patients with spinal malignancy. For the most part, the technique has been applied to patients with a limited life span, and those who are considered to be poor surgical candidates. Vertebroplasty may be performed to provide pain reduction, spinal stabilization, or both. Extensive osteolysis, particularly involving the posterior vertebral cortex, may lead to a leakage of the material used for vertebroplasty into the spinal canal. As a result, spinal cord or nerve root compression may occur. In contrast to the treatment of benign compression fractures, the treatment of neoplastic lesions often requires modification of the techniques used for vertebroplasty. Combining vertebroplasty with post-treatment irradiation is possible and useful.

The advantage of this technique for treatment of neoplastic disease is supported in the literature. Weill et al. reported a clear reduction in pain in $24(73 \%)$ of 33 procedures in a series of patients treated for metastatic lesions by vertebroplasty. ${ }^{[1]}$ Cotten et al. observed extra vertebral cement tors have a role in defining the most 'satisfied client,' and we are still far from understanding them all. We congratulate the authors for their preliminary experience.

José E. Cohen, Gustavo Rajz*

Departments of Neurosurgery and Radiology, Hadassah Hebrew University Medical Center, Jerusalem, *Department of Neurosurgery, Tel Hashomer Medical Center, Tel Aviv, Israel.

E-mail: jcohenns@yahoo.com

\section{Reference}

1. Cohen JE, Lylyk P, Ceratto R, Kaplan L, Umansky F, Gomori JM: Percutaneous vertebroplasty: technique and results in 192 procedures. Neurol Res $2004 ; 26: 41-9$ leakage in $72.5 \%$ of his patients. In almost all cases, the leaks were small and had no clinical relevance. ${ }^{[2]}$ Our own study on spinal metastases showed pain relief in $86 \%$ of all patients treated, with $23 \%$ cement leakage (no neurological signifi(ance). ${ }^{[3]}$

In space-occupying malignancies accompanied by neurological deficit, the decision to use vertebroplasty must be taken with extreme caution. In the presence of a tumor-derived bony destruction that allows leakage, the space-occupying effect associated with ventral compression or dislocation of the medulla will persist or be amplified by the surplus of PMMA.

Vertebroplasty treatment shows similar results with regard to pain relief for benign osteoporotic fractures and tumorderived vertebral destruction. However, complications are more frequent in patients with vertebral destruction. ${ }^{[4]}$

Michael Winking

Professor of Neurosurgery, Executive Direktor, Spine Center Osnabrueck, Lengericher Landstr. 19b, Osnabrueck, Germany. E-mail:winking@spine-osib.de

\section{References}

1. Weill A, Chiras J, Simon JM, Rose M, Sola-Martinez T, Enkaoua E. Spinal metastases: Indications for and results of percutaneous injection of acrylic surgical cement. Radiology 1996;199:241-7.

2. Cotten A, Dewatre F, Cortet B, Assaker R, Leblond D, Duquesnoy B, et al. Percutaneous vertebroplasty for osteolytic metastases and myeloma: effects of the percentage of lesion filling and the leakage of methyl methacrylate at clinical follow-up. Radiology 1996;200:525-30.

3. Winking M, Stahl J-P, Oertel M, Schnettler R, Böker D-K. PMMA vertebroplasty in patients with malignant vertebral destruction of thoracic and lumbar spine. GMS 1:DOC 08 (2003) (www.egms.de/en/gms/2003-1/00008.shtml)

4. Winking M, Stahl J-P, Oertel M, Schnettler R, Böker D-K. Pain treatment of osteoporotic vertebral collapse by percutaneous PMMA vertebroplasty. Acta Neurochirurgica 2004;146:469-76. 